Goldschmidt 2021 Abstract

https://doi.org/10.7185/gold2021.4214 http://dx.doi.org/10.1016/j.epsl.2015.02.030; [6] Bonifacie et al., 2008, doi: 10.1126/science.1150988;

\section{Chlorine isotopes from chlorides in sedimentary fluids of the ocean crust and the $\mathrm{Cl}$ budget of Earth surface Chlorine}

\author{
PIERRE AGRINIER ${ }^{1}$, MAGALI BONIFACIE ${ }^{2}$, GERARD \\ BARDOUX $^{3}$, THOMAS GIUNTA ${ }^{4}$, FRANCIS LUCAZEAU ${ }^{5}$ \\ AND MAGALI ADER ${ }^{6}$ \\ ${ }^{1}$ Université de Paris, Institut de Physique du Globe de Paris, \\ CNRS UMR 7154 \\ ${ }^{2}$ IPGP/CNRS UMR 7154 \\ ${ }^{3}$ Université de Paris, Institut de Physique du Globe de Paris, \\ CNRS \\ ${ }^{4}$ IFREMER \\ ${ }^{5}$ IPGP \\ ${ }^{6}$ Institut de Physique du Globe de Paris/CNRS UMR 7154 \\ Presenting Author: agrinier@ipgp.fr
}

In order to examine the budget of chlorine on Earth, we conduced a large investigation on pore fluids sedimentary successions from various oceanic tectonic contexts (subduction zones, ridge flank, oceanic plateau and basins). Despite relatively constant chloride contents over the depth profiles, we found a systematic decrease of $\delta^{37} \mathrm{Cl}$ values from $0 \%$ at the top of the sedimentary piles down to $-8.5 \%$ in the deepest sediments [1]. This systematic ${ }^{37} \mathrm{Cl}$-depletion of pore fluid chlorides is found in all studied sedimentary piles regardless of tectonic or sedimentary history. These trends cannot be explained by waterrock exchange reactions because alteration minerals have $\mathrm{Cl}$ contents that are too low to compensate for ${ }^{37} \mathrm{Cl}$ depletions. Accordingly, we assume that fluid-specific processes are responsible for such ${ }^{37} \mathrm{Cl}$-depletions in sediment porefluids and that ${ }^{37} \mathrm{Cl}$-enriched chlorides were expelled out of the sediments into the ocean.

We calculate that the pore fluids of the oceanic sediments have a mean $\delta^{37} \mathrm{Cl}$ of chlorides of $\approx-1.9 \pm 0.4 \%$. Therefore, the chlorine isotope budget of the chlorides at the surface of the Earth (seawater + evaporites + pore fluids of marine and continental sediments \{respectively: $2.7,1.9$ and $410^{19} \mathrm{~g}$ of $\mathrm{Cl}$ [2]\}) has a $\delta^{37} \mathrm{Cl}$ value around $-0.8 \pm 0.3 \%$. This value is significantly more negative than the $\delta^{37} \mathrm{Cl}$ of seawater $(=0 \pm 0.1$ $\%$ ) and that of evaporites $(\approx+0.3 \pm 0.1 \%$ o). Thus we deduce that $\mathrm{Cl}$ subducted into the mantle, transported by minerals in the crust that incorporate such ${ }^{37} \mathrm{Cl}$-depleted chlorine from the fluids, might have negative $\delta^{37} \mathrm{Cl}$ values, as recorded in metamorphosed oceanic crust rocks [3-5]. To maintain $\delta^{37} \mathrm{Cl}$ of surface $\mathrm{Cl}$ constant over geological time, there should be a output flux of $\mathrm{Cl}$ from the mantle with negative $\delta^{37} \mathrm{Cl}$ values. This is consistent with a mantle with negative $\delta^{37} \mathrm{Cl}$ values, and $\delta^{37} \mathrm{Cl} \leq-1.6 \%$ as reported in ref. [6].

Refs: [1] Agrinier et al., 2021 GCA [2] Eggenkamp, 2010, Doi 10.1007/978-3-642-28506-6; [3] Barnes et al., 2006, doi:10.1029/2006GC001296; [4] Bonifacie et al., 2008, doi:10.1016/j.gca.2007.10.010; [5] Selverstone and Sharp, 2015, 